\title{
How Do Students Shift from Task-Related to Task-Unrelated Thoughts?
}

\author{
Seffetullah Kuldas*, Shahabuddin Hashim, and Hairul Nizam Ismail
}

School of Educational Studies, Universiti Sains Malaysia (Malaysia).

\begin{abstract}
Título: ¿Cómo cambian los estudiantes de pensamientos relacionados con la tarea a pensamientos no relacionados?

Resumen: Aunque un creciente número de investigaciones psicológicas demuestran que los procesos de pensamiento inconsciente de los estudiantes pueden estar relacionados con las tareas, la investigación educativa todavía tiene que proporcionar evidencia empírica para esta relación en un contexto de aprendizaje en el aula. La literatura educativa también es poco concluyente en cuanto a si los estudiantes consciente o inconscientemente se involucran en pensamientos que no tienen relación con la tarea. Una cuestión clave que surge de esta indiferencia es si los pensamientos no relacionados con la tarea facilitan o inhiben el aprendizaje y el desempeño de las tareas cuando los estudiantes consciente e inconscientemente cambian su atención fuera de los pensamientos relacionados con la tarea. Esta revisión tiene como objetivo mejorar la comprensión de cómo los estudiantes cambian de pensamientos relacionados y no relacionados con la tarea. La revisión presenta una amplia gama de pruebas de cómo el cambio ocurre inconscientemente en lugar de conscientemente. El cambio inconsciente como resultado de las emociones negativas de los estudiantes puede inhibir en lugar de facilitar los procesos de aprendizaje. Se necesita más evidencia en la investigación educativa acerca de cómo ocurre el cambio en los pensamientos de los estudiantes dentro del aula.
\end{abstract}

Palabras clave: cambio inconsciente; emociones negativas; búsqueda de objetivos; mente distraída.

\section{Introduction}

Although learning as knowledge acquisition and application can happen without deliberate attention (Kuldas, Ismail, Hashim, \& Bakar, 2013), a widely held view is that better learning (i.e., the construction, application, and storage of coherent knowledge structures) within the classroom requires students to deliberately use their limited duration and capacity of working memory, that is, to consciously allocate their cognitive resources to taskrelated thoughts (Sweller, Ayres, \& Kalyuga, 2011). However, task-related thought processes can also be unconscious (e.g., the transition from having no idea to having an idea or from indecision to decision) when a learner's conscious attention is directed elsewhere (Dijksterhuis \& Nordgren, 2006). For example, a creative idea or solution may come to a student after or while taking a break. A creative solution or idea may pop into the conscious mind of a person who was not thinking of related problem at the moment (Dijksterhuis \& Meurs, 2006).

In contrast, 'task-unrelated thoughts' divert the attention away from task performance or task-relevant information (Smallwood, Baraciaia, Lowe, \& Obonsawin, 2003). The attention is often directed to oneself, taking the self as the object of attention (Smallwood, Obonsawin, \& Heim, 2003). An example of a task-unrelated thought is: "I was thinking about what I was going to do this evening" (Smallwood et al., 2004, p. 667). Such attentional shifts, also called 'zoning out' (Schooler et

* Correspondence address [Dirección para correspondencia]: Seffetullah Kuldas, School of Educational Studies, Universiti Sains Malaysia, 11800, Penang (Malaysia).E-mail: seffetu@gmail.com
Abstract: Although a growing body of psychological research shows that students' unconscious thought processes can be task-related, educational research has yet to provide empirical evidence for this relation in a classroom learning context. Educational literature is also inconclusive as to whether students consciously or unconsciously engage in task-unrelated thoughts. A key issue arising from this indistinctness is whether taskunrelated thoughts facilitate or inhibit learning and task performance when students consciously and when unconsciously shift their attention away from task-related thoughts. This review aims to enhance understanding of how students shift from task-related to task-unrelated thoughts. The review presents a wide range of evidence for how the shift happens unconsciously rather than consciously. The unconscious shift as a result of students' negative emotions can inhibit rather than facilitate learning processes. Further evidence is necessary for the required educational research on how the shift in students' thoughts happens within the classroom. Key words: unconscious shift; negative emotion; goal pursuit; mind wandering. al., 2004), can happen in a form of 'spontaneous cognition' such as mind wandering (Smallwood \& Schooler, 2013) or daydreaming (Buckner, Andrews-Hanna, \& Schacter, 2008) that almost all people experience on a daily basis.

Mind wandering as intentional engagement in taskunrelated thoughts about an external undemanding task, which is not related to a primary task, may yield better results, such as creative solutions and ideas (Baird et al., 2012). Reengaging in problem solving after mind wandering, for a long incubation period (i.e., a problem is set aside for a long rather than a short period of time, 15 instead of 5 minutes, prior to further attempts to solve it), may enhance creative problem solving (i.e., the incubation effect), especially when an incubation period is filled with interpolated tasks of low rather than high cognitive demand (Sio \& Ormerod, 2009). Such an incubation period usually allows for unconscious processing of previously encountered problems, thereby yielding creative solutions (Dijksterhuis \& Meurs, 2006; Ritter, Van Baaren, \& Dijksterhuis, 2012).

However, in demanding tasks (requiring deliberate attention), mind-wandering as the attentional shift from taskrelated to task-unrelated thoughts mostly leads to failures (Smallwood \& Schooler 2006), mistakes, or slowed performance (Buckner et al., 2008). In particular, having worrisome thoughts about failure and its consequences while learning or performing a task may deplete more cognitive resources and inhibit learning and task performance (Kuldas, Hashim, Ismail, \& Bakar, 2015). Findings related to students' motivation for achievement goals (Elliot \& McGregor, 1999; Pekrun, Elliot, \& Maier, 2006, 2009; Senko, Hulleman, \& Harackiewicz, 
2011) show that the allocation of cognitive resources to the avoidance of undesirable consequences increases anxiety levels and leaves fewer cognitive resources to exert for better learning and task performance. According to 'Resource Allocation Theory' (Ellis, 1990, Ellis et al., 1995, 1997a, 1997b; Seibert \& Ellis, 1991; Kliegel et al., 2005), other negative emotions (sadness and hopelessness) also bring taskirrelevant thoughts into conscious processing of memory tasks (e.g., learning and recalling letter sequences), divert attention from the task, and impair task performance.

The resource allocation theory (mainly concerned with effects of negative emotional states on working memory performance) is noteworthy as it claims that students consciously allocate their cognitive resources to the emotional thoughts, which inhibit their task performance. Contrary to the claim, a large body of empirical evidence, reviewed by Baumeister, Vohs, DeWall, and Zhang (2007), indicates that students' conscious thoughts about their intense emotions (feeling bad after failures and good after any significant progress in goal pursuits) promote learning and guide 'future behavior' (pursuing or avoiding an anticipated emotional outcome). Similar helpful effect on the 'current behavior' is generated by automatic-rapid affective responses. "The automatic affective responses may also remind the person of past emotional outcomes and provide useful guides as to what emotional outcomes may be anticipated in the present" (Baumeister et al., 2007, p.1). The more intense an emotion is (i.e., feeling bad due to a mistake rather than feeling good due to a success), the more cognitive reflection occurs (Baumeister, Bratslavsky, Finkenauer, \& Vohs, 2001). However, the evidence falls short of identifying task-unrelated thoughts those unduly occupy the valuable cognitive resources in relation to current and anticipated emotional states as well as to their conscious and unconscious aspects.

Due to affective thought processes, dissociations between the allocation of cognitive resources and its conscious awareness are often apt to happen (Kuldas et al., 2015; Schooler, 2002). An emotional experience (e.g., feeling of pleasure or liking) during task performance can be entirely unconscious (inaccessible to introspection) and may drive human behavior, even when a student is motivated and attentive for describing his/her feelings correctly (Winkielman \& Berridge, 2004). Examples of such unconscious thoughts and behaviors are documented in various literature (neuropsychological, perceptual, cognitive, educational, social, and psychoanalytic). There is ample evidence that unconscious thoughts and defense mechanisms (e.g., suppression of unwanted thoughts) inevitably influence students' cognitive learning and task behavior within classroom contexts (Dörnyei, 2000; Kuldas \& Bulut, 2016; Kuldas et al., 2015). For instance, empirical evidence (Baird, Smallwood, Fishman, Mrazek, \& Schooler, 2013) suggests that students may even lack conscious awareness of an unwanted thought they had attempted to suppress.

Thus, the unconscious shift (unconscious thought process) can be referred to that when students are unaware of (a) how they initiate, maintain, develop, or apply thoughts; (b) how the unconsciously initiated, developed, or applied thoughts facilitate or inhibit their learning and task performance; and (c) when they become aware of the shift but unable to articulate reasonably how it happened (Kuldas, Hashim, Ismail, Samsudin, \& Bakar, 2014a). In a nutshell, unconscious interactions within and between affects and motives (fears, desires, beliefs) impact conscious cognition, thereby leading to the shift in thoughts. As this proposition needs to be adequately tested within the classroom, the various literature deserves scrutiny for the sake of providing insights into the question: How does this shift, from task-related to task-unrelated thoughts, happen unconsciously?

To take into account the different forms of unconscious thought processes (i.e., automatic, affective, cognitive, and motivational) is essential for understanding how students unconsciously engage in task-unrelated and -related thoughts. To enhance the understanding, the present review with three main sections aims at presenting distinct evidence for: (a) how thoughts are initiated, maintained, applied, and particularly related to unconscious affective responses; (b) how affective thought processes influence goal pursuits; and (c) how the unconscious shift in thoughts (the initiation, sustainment, and application of thoughts) happens.

\section{How are Thoughts Initiated and Associated with Subsequent Actions?}

Whether or not an initiation of thoughts and the corresponding decision to act happen consciously (i.e., whether the conscious is preceded by the unconscious) is a very contentious issue in terms of possibility of detecting a specific neural network or a particular region in the brain that is responsible for the initiation and decision of acts (see Radder \& Meynen, 2013; Schlosser, 2014). Wegner and Wheatley (1999) argued that unconscious processes give rise to conscious thought about the intention or decision to act; therefore, real causes underlying human behaviors originate from the unconscious rather than the conscious. Empirical studies on a decisionmaking process (Haynes, 2011; Libet, 1999; Schlosser, 2012; Soon, Brass, Heinze, \& Haynes, 2008) illustrated that the unconscious activation of thoughts (urges) preceded their conscious elicitation. Deciding to act arose prior to conscious awareness of activated urges. Yet, participants could consciously follow or reject the unconsciously elicited urge. These findings, however, fall short of explaining: (a) how much control a learner has over the interaction between unconscious and conscious thoughts (Wegner, 2002), and (b) how or when unconscious thoughts become conscious, and vice versa (Berlin, 2011).

A series of studies on similar issues found a lack of conclusive evidence for students' conscious awareness and the control of how unconscious thoughts impact their conscious behaviors and how they engage in task-unrelated thoughts. For instance, Giambra and Grodsky (1989; Grodsky \& Giambra, 1990) examined task-unrelated thoughts during reading texts by considering both interest and difficulty. The researchers trained participants to distinguish between their 
intentional and unintentional engagements in thoughts unrelated to the task. As a result, even successful readers regularly reported unintentional engagement in task-unrelated thoughts during reading. Furthermore, attentional demands (taskdifficulty) were unrelated to the frequency of occurrence of task-unrelated thoughts. Difficult and easy texts brought about frequent task-irrelevant thoughts similarly, whereas dull text more often than easy text gave rise to task-unrelated thoughts. One may argue that the report of the unintentional engagement does not necessarily mean that participants were unaware of it, given that these studies focused only on intention rather than awareness. However, before a reader noticed that his/her mind wandered while reading, his/her conscious awareness was temporarily absent. In other words, due to the fact that participants were unaware of how they got engaged in task-irrelevant thoughts, lacking intention is equivalent to lacking awareness (see Schooler, 2002; Schooler et al., 2004).

In similar studies, the engagement in task-unrelated thoughts is mainly ascribed to students' emotions that act as the on/off switch to motivation, unconsciously initiating or sustaining a goal-directed behavior (Kuldas et al., 2014a). Emotion is conceptualized as a dynamic process based on subjective appraisals of significant events (Scherer, 2009) whereby initiates, accelerates, alters, or interrupts information processing (Pekrun, Goetz, Titz, \& Perry, 2002). An appraisal process is primarily intuitive, immediate, and outside of conscious awareness (Robinson \& Clore, 2001), but later can become a conscious response to affective stimuli that prepare action readiness (Scherer, 2009). The human brain automatically, effortlessly, and rapidly reacts to affective stimuli, thereby eliciting various emotions (e.g., fear, anger, or disgust) and generating affective responses, reactions, or actions (Öhman, 2002; Siegel \& Weinberger, 2009; Westen, 2006). Emotional reactions can occur with minimal stimulation, and thus, precede and alter subsequent cognitions (Murphy \& Zajonc, 1993).

Accordingly, students can automatically appraise their learning and task performance (Pekrun, 2006). The autoemotional evaluation (i.e., undeliberate conscious processing) is likely to serve as a guide for a learner to react appropriately (approach or avoid) to all stimuli independently of his/her goal-directed cognition (Chen \& Bargh, 1999). Baumeister and colleagues (2007) stated that auto-emotional reactions do not have to rest on conscious cognition and may often consist of no more than a simple feeling that something is good or bad, to be approached or avoided: "the feeling of liking or disliking some stimulus may require nothing more than perceiving the stimulus and making one association" (p.3). Therefore, students can auto-emotionally react to stimuli (e.g., a teacher's tone of voice) around a classroom setting. "Such automatic emotional reactions are based on earlier experiences that have left an association (a memory trace) between the emotion experienced in a situation and a specific element of the situation" (Hannula, 2006, p. 171, see also Smith and DeCoster, 2002 for a review of empirical evidence).

\section{The Interplay between Emotions and Goal Pursuits of Students}

Emotions as conscious or automatic feedbacks/feelings can be very useful for almost any sort of goal pursuit, because they guide behavior towards the goal (Baumeister et al., 2007). Emotions may arise in the course of goal striving whenever a student feels that it is likely to achieve the goal. This anticipation of success usually evokes positive feelings and fosters further efforts towards the goal (Custers \& Aarts, 2010; Oatley \& Johnson-Laird, 1987). Moreover, positive feelings may induce coasting, thereby shifting attention and effort to other goals or tasks, for which may be needed more. In contrast, the anticipation of a lower or no success evokes negative feelings and leads to disengagement from the goal (Wrosch, Scheier, Miller, Schulz, \& Carver, 2003). Scherer (1999) highlighted that an evaluation of whether an emotional experience is desirable or undesirable in terms of subjective needs, values, and goals, is mostly subjected to unconscious appraisals. Leaners are able to appraise their feelings consciously, but not all the time or instantaneously; the conscious mind allows for a limited control over various effects of desires, hopes, or fears on the ways they think, behave, or learn (Bargh \& Chartrand, 1999; Bargh \& Ferguson, 2000; Kuldas, Satyen, Ismail, \& Hashim, 2014b).

The interplay between emotion, motivation, and cognition is readily observable in students' achievement goals (Linnenbrink, 2006), while they are striving to pursue a goal or to avoid an undesirable achievement (Ainley, 2006; Kim \& Pekrun, 2014; Kuldas et al., 2014b; Pekrun, 2006). Linnenbrink, Ryan, and Pintrich (1999) reported that mastery goals (e.g., better learning) decrease negative affect, whereby enhance working memory functioning. In contrast, performance goals (e.g., better task performance) increase negative affect whereby decrease working memory performance. This finding suggests that students who are pursuing mastery goals usually perceive difficult tasks as a challenge; therefore, they are apt to be less concerned with failure and may not be easily annoyed, frustrated, or anxious. In contrast, the perception of challenge may increase negative affect of students with performance goals, the ones who strive to avoid failure in demonstrating their ability in comparison to others. In a similar way, Pekrun and colleagues (2006) stated that masteryapproach goals usually promote positive emotions (sustaining motivation), whereas performance-avoidance goals tend to promote negative emotions and insufficient motivation. Some negative emotions (e.g., panic, insecurity, and high anxiety) can bring about feeling incompetent, thereby inhibiting learning and task performance. The opposite can occur with other negative (e.g., mild anxiety) and positive emotions, such as curiosity (Kuyper, Van Der Werf, \& Lubbers, 2000). However, it should be noted that, these interactions between emotions and goals do not necessarily require a conscious intervention. Bargh and colleagues (Gollwitzer, Lee-Chai, Barndollar, \& Trötschel, 2001) argued that "goals can be triggered outside of awareness and then run to completion, attaining 
desired outcomes. No conscious intervention, act of will, or guidance is needed for this form of goal pursuit" (p. 1014). They found that performance goals can become activated without conscious and deliberate choice; these unconscious goals can promote attainment of the desired outcome and persistence in task performance in the face of obstacles. However, a similar argument for mastery goals could be examined to explain whether a performance goal draws on unconscious cognition more than a mastery goal.

Students' commitment to a particular goal can make them sensitized to cues associated with the goal, whereby they can notice and think of the cues, which may be either in their mind or a stimulus in the surrounding environment. Such an association with any desired achievement-goal is accompanied and perhaps preceded by full emotional arousal, which is not yet conscious (Klinger, 2013). Therefore, as Klinger emphasized, the act of noticing is not necessarily a conscious act all the time. For instance, a student may notice that his/her mind had wandered without recognizing the associated frustration. When experiencing such negative emotions, the student lacked momentary conscious awareness that his/her attention had become dissociated from task-relevant thoughts (Schooler, 2002). In such a case, students are usually unaware of how the shift occurs or how their attention is split (Smallwood \& Schooler, 2006).

Furthermore, when some students become aware of the shift, they are usually unable to articulate reasonably how the shift happened (Schooler, 2002) or to explain motives for their own behavior (Evans, Morgan, \& Tsatsaroni, 2006), especially when they are stressed (Antrobus, Coleman, \& Singer, 1967). In an early experimental study, Antrobus, Singer, and Greenberg (1966) delivered distressing information that induced a personally salient concern and thus increased taskirrelevant cognitive activities, such as daydreaming and fantasies. The contents of daydreams were a mixture of freely wandering thoughts about past and present experiences, any personal concern from mundane recounts of recent happenings to expectations about the future (Buckner et al., 2008). As Smallwood and Schooler (2013) stated, such mind wandering can be seen as a goal-driven process (but not directed toward the primary task) without explicit awareness and intention (controlled processing). Therefore, as a shift attention away from a primary task toward task-unrelated inner thoughts, memories, fantasies, or feelings, mind wandering can lead to failures in task performance (Smallwood \& Schooler, 2013).

Further neurocognitive findings confirm that due to emotional responses to goal-related cues, particularly under the pressure of prospective loss or failure to achieve a goal, cognitive resources can be devoted to mind wandering without the mind-wanderer being aware of this devotion (Klinger, 2013). The awareness of engagement in mind wandering happens at different time than its unconscious initiation and maintenance (Schooler et al., 2011). In other words, mind wandering and its conscious awareness are not observable at the same time, although they partially or totally share the same neural networks in the brain (Schooler et al., 2011). According to Schooler and colleagues, this sharing does not allow them to occur simultaneously or even with an equal frequency. Therefore, as Schooler (2002) argued, experiencing mind wandering should be disassociated from knowing/noticing it (i.e., taking into account the difference between initiating, maintaining, and noticing mind wandering).

The suggestion however raises a further issue: how to distinguish cognitive activities and affects/motives that initiate the shift from those that ensure the continuity of the shift? How the shift in thoughts starts may differ from how the shift continues or ends. Smallwood (2013) highlighted that current scientific methods allows for no identification of the moment that a given mind wandering episode ends. "Participants may forget to indicate that they had mind-wandered or may not even notice that they had temporarily lost track of what they were doing" (p. 522). This inability to characterize the termination of a mind wandering (i.e., unknowing when an internal train of thought is ended) creates significant challenges in explaining how students redirect their attention back to the task at hand, prioritize their goals or needs, and how their goals become inhibitory, facilitatory, or necessary to reach another goal.

In consequence, as Dörnyei (2000) contended, a merely cognitive approach is not adequate for understanding "how multiple goals are prioritized and how the hierarchy of superordinate and subordinate goals is structured" (p. 537). Therefore, various motivational influences that are not under students' direct control should be taken into consideration. This suggestion reaffirms that "as we approach the 21 st century, the role of affect and less conscious processes is reemerging as a central theme" (Eccles, Wigfield, \& Schiefele, 1998, p. 1074). Students do not merely consciously bring their interests, beliefs, or wants into learning processes, but also do so unconsciously even when they intentionally remember, express a wish, or make a decision (Jacoby, Lindsay, \& Toth, 1992; Kuldas, Bakar, \& Ismail, 2012). While referring to interests and beliefs, they can unconsciously manipulate their wishes, desires, and thoughts into whatever they wish to obtain, even if whatever they want is not actually perceptible to their senses (Kavanagh, Andrade, \& May, 2005). In these processes, students cannot easily avoid the unconscious effect of desires, expectations, or evaded thoughts over their cognitive and affective thoughts processes and behavioral tendencies. Hence, as Hannula (2006) suggested, the unconscious in students' mind and motivation should be taken into consideration in order to better understand their behavior (how they use their cognitive resources) in a classroom setting.

\section{The Automatic and Unconscious Shift in Thoughts}

To understand how the shift starts, continues, or ends requires precisely identifying how sensory organs and the unconscious mind sort out information relevant or irrelevant to a task at hand, particularly when conscious attention (awareness and control over information processing) is directed elsewhere. Kastner and Ungerleider (2000) maintained that the attentional 
capacity of the visual system to allow processing multiple stimuli at a given time is limited. Therefore, "in the absence of directed attention, multiple stimuli in the visual field interact with each other in a mutually suppressive way" (Kastner, De Weerd, Desimone, \& Ungerleider, 1998, p. 110). According to Kastner and colleagues, directing attention to a stimulus counteracts the suppressive influence of nearby stimuli; this suppressive or competitive mechanism seems serving to filter out irrelevant or unwanted information in cluttered visual scenes. Such automatic monitoring of thoughts can be ascribed to the limited capacity.

However, this ascription does not clarify how taskirrelevant or unwanted thoughts elude the suppressive mechanism, shift the focus of attention, and reduce the attentional capacity. This issue becomes clearer in further findings that suggest a dynamic-motivational aspect of thought processes, encompassing perceptual, emotional, and cognitive behavior (Rothermund, Gast, \& Wentura, 2011). Gawronski, Deutsch, and Strack (2005) showed that the perception and cognitive information processing of negative and positive stimuli vary according to motivational orientations (goals and needs), approach, or avoidance tendencies. Therefore, human perception, attention, and judgment can be under the influence of either 'negativity bias' (Baumeister et al., 2001; Öhman, Flykt, \& Esteves, 2001) or 'positivity bias' (Balcetis \& Dunning, 2006; Juth, Lundqvist, Karlsson, \& Öhman, 2005). The former suggests that negative stimuli attract and hold attention automatically, while the later means that perceptual and cognitive processing is biased towards positive stimuli. These findings confirm McGinnies's (1949) suggestion that perceptions are also structured with respect to reward, need fulfilment, attitudinal orientation, potential anxiety, and release from tension. McGinnies suggested a perceptual defense or filtering mechanism of visual stimuli that "serves, in many instances, to protect the observer as long as possible from an awareness of objects which have unpleasant emotional significance for him" (p. 244). The perceptual defense allows humans to unconsciously suppress or even block some sensory information related to negative emotional stimuli or events (Erdelyi, 1974).

As Erdelyi (2006) pointed out, such evidence as in abovementioned studies substantiates a basic proposition of 'Psychoanalytic Theory of the Unconscious Mind' that both human sensory organs and the unconscious mind preclude undesirable information from entering into the conscious mind. On the basis of their experimental findings, Anderson and colleagues (Green, 2001; Levy, 2009) proposed a suppression mechanism as posited by Freud: when people encounter stimuli that remind them of unwanted thoughts or unpleasant past experiences, they consistently try to avoid such thoughts from entering their conscious awareness. Further evidence also indicates that humans unconsciously approach making a new decision that is associated with desirable thoughts, but avoid such an approach when thoughts are undesirable (Epstein, 1994; Chen \& Bargh, 1999). A growing body of such evidence for the unconscious approach and avoidance behavior has been considered as the experimental foundation for the theory of the unconscious mind, supporting that conscious behavior has a preliminary unconscious guidance (see Bargh \& Morsella, 2008; Berlin, 2011; Beutel, Stern, \& Silbersweig, 2003; Kuldas \& Bulut, 2016; Solms \& Panksepp, 2012; Westen, 1998, 1999). Further research is needed to test this proposition of the unconscious mind theory in relation to a learning task in a classroom setting.

However, as Kihlstrom (2008) stressed, the evidence does not necessarily mean that the unconscious is a repository of primitive sexual and aggressive instincts and therefore mental contents are rendered unconscious by a defensive mechanism, such as repression. The evidence is rather for "the cognitive unconscious - cognitive processes that operate automatically and unconsciously" (Kihlstrom, 2008, p. 589), referring to percepts, memories, knowledge, and thoughts that are inaccessible to conscious awareness. The cognitive unconscious allows humans to manipulate information implicitly and associatively.

Notwithstanding the validity of Kihlstrom's argument, cognitive unconscious cannot be easily dissociated from the unconscious mind; both propose mental processes that are inaccessible to conscious awareness and control. Evidence for both theory indicates that goal-directed cognition is accompanied by: (a) unconscious 'associative memory networks' (e.g., beliefs, wishes, desires, and thoughts), and (b) 'unconscious procedures' such as affects, motives, defenses (Westen, 1998). An activation of thoughts is an evocation of the related functions such as affects/motives (e.g., anxiety). These unconscious networks and procedures alter emotional states, guide human behavior, and thus, influence most conscious experiences (see Greenwald, 1992; Kihlstrom, Barnhardt, \& Tataryn, 1992; Westen, 1999, 2006). Hence, the assertion that recent findings does not support the unconscious mind is inconclusive.

As a result, there is a dynamic interplay between affect, motivation, and cognition; a negative affective stimulus can trigger related cognition (evoking mode-congruent thoughts), thereby defocusing attention and reducing both informationprocessing time and attentional capacity for task-related thoughts (Roets \& Van Hiel, 2011). On one hand, therefore, deliberate attempts to develop thoughts related to positive emotional states (e.g., happiness) may involve suppression of other thoughts related to the counterparts (e.g., sadness). On the other hand, conscious attempts to monitor or to suppress unwanted thoughts may unwittingly initiate or automatically activate more evaded thoughts (Wegner, 1997). As these thought processes lead to high cognitive load (i.e., taking up valuable space in working memory) and thus undermine conscious capacity to notice the occurrence of a suppressed thought, little or no cognitive resource would be available to regulate thoughts and emotions (Baird et al., 2013) that are germane to learning. In other words, available cognitive capacity can be insufficient for conscious/deliberate processing of further task-related thoughts, which, in turn, substantially de- 
crease motivation for task performance (Roets, Van Hiel, \& Kruglanski, 2013).

However, the distinctive descriptions of the human mind and sensory organs give rise to a further issue: how to distinguish between the bias effect, the perceptual defense, and the suppressive function of visual stimuli, if processing positive information automatically filters or blocks negative information, and vice versa? Further studies on this issue are needed to elaborate the extent of the distinctions (if the functions are mutually exclusive). Prospective findings need to be examined in relation to the unconscious mind theory and to other distinctively described unconscious (e.g., automatic, implicit, intuitive, associative, or cognitive unconscious) initiation, sustainment, and application of thoughts. A convincing reason for these distinctive descriptions might be that the functions of human mind and sensory organs may not be easily grouped under a single heading (i.e., the conscious and unconscious mind). Instead, the terms 'conscious processes' and 'unconscious processes' (Westen, 1999), or as Evans (2008) proposed, 'System 1' (unconscious) and 'System 2' (conscious), can be used in further examinations of how students' unconscious thoughts and behaviors facilitate their conscious acts (e.g., how unconscious processes facilitate task-related thoughts, contributing to learning and task performance).

\section{Conclusion}

To enhance the understanding of how students shift the allocation of cognitive resources from task-related to taskunrelated thoughts, this narrative review has synthesized evidence for unconscious cognitive and affective/motivational thought processes. The reviewed educational literature on the conscious use of cognitive resources remains unclear how students consciously do the shift: what are their conscious reasons to devote the resources to task-unrelated thoughts those impair learning and task performance? According to a consensus among the reviewed studies on the cognitive, perceptual, and affective (motivational) aspects of learning, students cannot be always conscious of their learning processes, nor do they ensure a desired change in their behavior by being conscious learners. Engagement in task-unrelated thoughts often happens outside of conscious control, intention, and the awareness. Therefore, the review has argued that the shift mostly takes place without students' conscious awareness and control, but how it starts may differ from how it continues or ends. Hence, how or when students engage in task-unrelated thoughts should be disassociated from how they maintain and notice. To make this dissociation, further research is needed to distinguish cognitive activities and affects/motives (a) that initiate the shift from those that ensure the continuity of the shift; and (b) that end the shift or a mind wandering inhibitory to learning and task performance (explaining how students redirect their attention back to the task at hand).

The reviewed studies lack a consensus about whether the cognitive processing capacity or the unconscious associative memory networks (wishes, beliefs, and thoughts) and unconscious procedures (affects, motives, defenses) primarily obstruct the conscious use of cognitive resources for taskrelevant thoughts. The unconscious mind theory suggests that both human sensory organs and the unconscious mind prevent a good part of information, which is particularly undesirable, from entering into the conscious mind, while the other perspectives generally point out the constraints of $\operatorname{cog}$ nitive capacity. Notwithstanding the lack of consensus, the perspectives concur that (a) the perceptual and cognitive processing of negative and positive stimuli can vary according to motivational goals/needs, and (b) the perceptual and cognitive defense (suppression mechanism) serves to avoid conscious awareness of some information patterns related to unpleasant emotional stimuli.

This review has mainly concluded that taking merely conscious account of the main issue (how the shift occurs) falls short of understanding (a) what determines the content of task-unrelated thoughts to be inhibitory to task performance (e.g., how thoughts are activated and associated with subsequent acts, such as the unconscious evocation of thoughts about failures instead of successful achievements), (b) how students prioritize (superordinate and subordinate) their goals/needs for the resource allocation. To take into account unconscious affects/motives is central to the understanding. Students need the unconscious cognitive and affective/motivational processing as much as they need the counterpart in learning processes. For instance, students' performance goals can be activated with or without deliberate and control attention, thereby facilitating achievement of the desired outcome and persistence in task performance in the face of obstacles. However, neither the conscious nor the unconscious always facilitates every learning case; either of them may impede learning and performance of a cognitive task under time constraint and uncertainty, or with distractive emotional (motivational) values of the task. For such cases, a precise differentiation between conscious and unconscious motivation for the allocation of cognitive resources to taskunrelated thoughts is needed. In particular, the circumstances in which unconscious affective thoughts motivate or demotivate students to exert the necessary amount of cognitive resources for better learning should be clearly identified, so as to provide a guideline for teachers, explaining how to help students benefit from the unconscious cognitive and motivational processing. To provide new insights into these issues, further studies might revise and draw on the resource allocation theory and the unconscious mind theory to collate evidence for how negative emotional experiences (affective thought processes) lead to task-unrelated thoughts; to test if the inhibitory shift from task-related and task-unrelated thoughts occurs consciously.

Acknowledgment.- The first author gratefully acknowledges the support by Institute of Postgraduate Studies, Universiti Sains Malaysia, under the USM PhD Fellowship Scheme. 


\section{References}

Ainley, M. (2006). Connecting with learning: Motivation, affect and cognition in interest processes. Educational Psychology Review, 18, 391-405. doi:10.1007/s10648-006-9033-0

Anderson, M. C., \& Green, C. (2001). Suppressing unwanted memories by executive control. Nature, 410, 366-369. doi:10.1038/35066572

Anderson, M. C., \& Levy, B. J. (2009). Suppressing unwanted memories. Current Directions in Psychological Science, 18, 189-194. doi:10.1111/j.14678721.2009.01634.x

Antrobus, J. S., Coleman, R., \& Singer, J. L. (1967). Signal detection performance by subjects differing in predisposition to daydreaming. Journal of Consulting Psychology, 31, 487-491. doi:10.1037/h0024969

Antrobus, J. S., Singer, J. L., \& Greenberg, S. (1966). Studies in the stream of consciousness: Experimental enhancement and suppression of spontaneous cognitive processes. Perceptual and Motor Skills, 23, 399-417. doi:10.2466/pms.1966.23.2.399

Baird, B., Smallwood, J., Fishman, D. J. F., Mrazek, M. D., \& Schooler, J. W. (2013). Unnoticed intrusions: Dissociations of meta-consciousness in thought suppression. Consciousness and Cognition, 22, 1003-1012. doi:10.1016/j.concog.2013.06.009

Baird, B., Smallwood, J., Mrazek, M. D., Kam, J. W. Y., Franklin, M. S., \& Schooler, J. W. (2012). Inspired by distraction: Mind wandering facilitates creative incubation. Psychological Science, 23, 1117-1122. doi:10.1177/0956797612446024

Balcetis, E., \& Dunning, D. (2006). See what you want to see: Motivational influences on visual perception. Journal of Personality and Social Psychology, 91, 612-625. doi:10.1037/0022-3514.91.4.612

Bargh, J. A., \& Chartrand, T. L. (1999). The unbearable automaticity of being. American Psychologist, 54, 462-479. doi:10.1037/0003-066X.54.7.462

Bargh, J. A., \& Ferguson, M. J. (2000). Beyond behaviorism: On the automaticity of higher mental processes. Psychological Bulletin, 126, 925-945. doi:10.1037//0033-2909.126.6.925

Bargh, J. A., \& Morsella, E. (2008). The unconscious mind. Perspectives on Psychological Science, 3, 73-79. doi:10.1111/j.1745-6916.2008.00064.x

Bargh, J. A., Gollwitzer, P. M., Lee-Chai, A., Barndollar, K., \& Trötschel, R. (2001). The automated will: Nonconscious activation and pursuit of behavioral goals. Journal of Personality and Social Psychology, 81, 1014-1027. doi:10.1037/0022-3514.81.6.1014

Baumeister, R.F., Bratslavsky, E., Finkenauer, C., \& Vohs, K. D. (2001). Bad is stronger than good. Review of General Psychology, 5, 323-370. doi:10.1037/1089-2680.5.4.323

Baumeister, R. F., Vohs, K. D., DeWall, C. N., \& Zhang, L. (2007). How emotion shapes behavior: Feedback, anticipation, and reflection, rather than direct causation. Personality and Social Psychology Review, 11, 167-203. doi:10.1177/1088868307301033

Berlin, H. A. (2011). The neural basis of the dynamic unconscious. Neuropsychoanalysis, 13(1), 5-31. doi:10.1080/15294145.2011.10773654

Beutel, M. E., Stern, E., \& Silbersweig, D. A. (2003). The emerging dialogue between psychoanalysis and neuroscience: Neuroimaging perspectives. Journal of the American Psychoanalytic Association, 51, 773-801. doi:10.1177/00030651030510030101

Buckner, R. L., Andrews-Hanna, J. R., \& Schacter, D. L. (2008). The brain's default network. Annals of the New York Academy of Sciences, 1124, 1-38. doi:10.1196/annals.1440.011

Chen, M., \& Bargh, J. A. (1999). Consequences of automatic evaluation: Immediate behavioral predispositions to approach or avoid the stimulus. Personality and Social Psychology Bulletin, 25, 215-224. doi:10.1177/0146167299025002007

Custers, R., \& Aarts, H. (2010). The unconscious will: How the pursuit of goals operates outside of conscious awareness. Science, 329, 47-50. doi:10.1126/science. 1188595

Dijksterhuis, A., \& Meurs, T. (2006). Where creativity resides: The generative power of unconscious thought. Consciousness and Cognition, 15, 135146. doi:10.1016/j.concog.2005.04.007

Dijksterhuis, A., \& Nordgren, L. F. (2006). A theory of unconscious thought. Perspectives on Psychological Science, 1, 95-109. doi:10.1111/j.17456916.2006.00007.x
Dörnyei, Z. (2000). Motivation in action: Towards a process-oriented conceptualisation of student motivation. British Journal of Educational Psychology, 70, 519-538. doi:10.1348/000709900158281

Eccles, J. S., Wigfield, A., \& Schiefele, A. (1998). Motivation to succeed. In W. Damon \& N. Eisenberg (Eds.), Handbook of Child Psychology: Social, Emotional, and Personality Development (5th ed. Vol. 3, pp. 1017-1095). New York: John Wiley \& Sons.

Elliot, A. J., \& McGregor, H. A. (1999). Test anxiety and the hierarchical model of approach and avoidance achievement motivation. Journal of Personality and Social Psychology, 76, 628-644. doi:10.1037/00223514.76.4.628

Ellis, H. C. (1990). Depressive deficits in memory: Processing initiative and resource allocation. Journal of Experimental Psychology: General, 119, 60-62. doi:10.1037/0096-3445.119.1.60

Ellis, H. C., Moore, B. A., Varner, L. J., \& Ottaway, S. A., Becker, A. S. (1997a). Depressed mood, task organization, cognitive interference, and memory: Irrelevant thoughts predict recall performance. Journal of Social Behavior \& Personality, 12, 453-470.

Ellis, H. C., Ottaway, S. A., Varner, L. J., Becker, A. S., \& Moore, B. A. (1997b). Emotion, motivation, and text comprehension: The detection of contradictions in passages. Journal of Experimental Psychology: General, 126, 131-146. doi:10.1037/0096-3445.126.2.131

Ellis, H. C., Varner, L. J., Becker, A. S., \& Ottaway, S. A. (1995). Emotion and prior knowledge in memory and judged comprehension of ambiguous stories. Cognition \& Emotion, 9, 363-382. doi:10.1080/02699939508408972

Epstein, S. (1994). Integration of the cognitive and the psychodynamic unconscious. American Psychologist, 49, 709-724. doi:10.1037/0003066X.49.8.709

Erdelyi, M. H. (1974). A new look at the new look: Perceptual defense and vigilance. Psychological Review, 81(1), 1-25. doi:10.1037/h0035852

Erdelyi, M. H. (2006). The unified theory of repression. Behavioral and Brain Sciences, 29, 499-551. doi:10.1017/S0140525X06009113

Evans, J. St. B. T. (2008). Dual-processing accounts of reasoning, judgment, and social cognition. Annual Review of Psychology, 59, 255-278. doi:10.1146/annurev.psych.59.103006.093629

Evans, J., Morgan, C., \& Tsatsaroni, A. (2006). Discursive positioning and emotion in school mathematics practices. Educational Studies in Mathematics, 63, 209-226. doi:10.1007/s10649-006-9029-1

Gawronski, B., Deutsch, R., \& Strack, F. (2005). Approach/avoidancerelated motor actions and the processing of affective stimuli: Incongruency effects in automatic attention allocation. Social Cognition, 23, 182 203. doi:10.1521/soco.23.2.182.65627

Giambra, L. M., \& Grodsky, A. (1989). Task-unrelated images and thoughts while reading. In J. Shorr, P. Robin, J. A. Connella, \& M. Wolpin (Eds.), Imagery: Current perspectives (pp. 26-31). New York: Plenum Press.

Greenwald, A. G. (1992). New look 3: Unconscious cognition reclaimed. American Psychologist, 47, 766-779. doi:10.1037/0003-066X.47.6.766

Grodsky, A., \& Giambra, L. M. (1990). The consistency across vigilance and reading tasks of individual differences in the occurrence of taskunrelated and task-related images and thoughts. Imagination, Cognition and Personality, 10, 39-52. doi:10.2190/6QG5-CXVV-4XUR-7P3K

Hannula, M. S. (2006). Motivation in mathematics: Goals reflected in emotions. Educational Studies in Mathematics, 63, 165-178. doi:10.1007/s10649-005-9019-8

Haynes, J. D. (2011). Beyond Libet: Long-term prediction of free choices from neuroimaging signals. In S. Dehaene \& Y. Christen (Eds.), Characterizing consciousness: From cognition to the clinic? (pp. 161-174). Springer. doi:10.1007/978-3-642-18015-6

Jacoby, L. L., Lindsay, D. S., \& Toth, J. P. (1992). Unconscious influences revealed: Attention, awareness, and control. American Psychologist, 47 802-809. doi:10.1037/0003-066X.47.6.802

Juth, P., Lundqvist, D., Karlsson, A., \& Öhman, A. (2005). Looking for foes and friends: Perceptual and emotional factors when finding a face in the crowd. Emotion, 5, 379-395. doi:10.1037/1528-3542.5.4.379 
Kastner, S., \& Ungerleider, L. G. (2000). Mechanisms of visual attention in the human cortex. Annual Review of Neuroscience, 23, 315-341. doi:10.1146/annurev.neuro.23.1.315

Kastner, S., De Weerd, P., Desimone, R., \& Ungerleider, L. G. (1998). Mechanisms of directed attention in the human extrastriate cortex as revealed by functional MRI. Science, 282, 108-111. doi: $10.1126 /$ science. 282.5386 .108

Kavanagh, D. J., Andrade, J., \& May, J. (2005). Imaginary relish and exquisite torture: The elaborated intrusion theory of desire. Psychological Review, 112, 446-467. doi:10.1037/0033-295X.112.2.446

Kihlstrom, J. F. (2008). The psychological unconscious. In O. P. John, R. Robins \& L. Pervin (Eds.), Handbook of personality: Theory and research (3rd ed., pp. 583-602). New York: Guilford.

Kihlstrom, J. F., Barnhardt, T. M., \& Tataryn, D. J. (1992). The psychological unconscious: Found, lost, and regained. American Psychologist, 47, 788-791. doi:10.1037/0003-066X.47.6.788

Kim, C. M., \& Pekrun, R. (2014). Emotions and motivation in learning and performance. In J. M. Spector, M. D. Merrill, J. Elen, \& M. J. Bishop (Eds.), Handbook of research on educational communications and technology (4th ed., pp. 65-75). New York: Springer. doi:10.1007/978-1-4614-3185-5_6

Kliegel, M., Jäger, T., Phillips, L. H., Federspiel, E., Imfeld, A., Keller, M., \& Zimprich, D. (2005). Effects of sad mood on time-based prospective memory. Cognition \& Emotion, 19, 1199-1213. doi:10.1080/02699930500233820

Klinger, E. (2013). Goal commitments and the content of thoughts and dreams: Basic principles. Frontiers in Psychology, 4, 415. doi:10.3389/fpsyg.2013.00415

Kuldas, S., \& Bulut, S. (2016). What is called self in educational research and practice? Basic and Applied Social Psychology, 38, 200-211. doi:10.1080/01973533.2016.1198260

Kuldas, S., Bakar, A. Z., \& Ismail, H. N. (2012). The role of unconscious information processing in the acquisition and learning of instructional messages. Electronic Journal of Research in Educational Psychology, 10, 907940.

Kuldas, S., Hashim, S. B., Ismail, H. N., Samsudin, M. A., \& Bakar, A. Z. (2014a). The unconscious allocation of cognitive resources to taskrelevant and task-irrelevant thoughts. Australian Journal of Educational \& Developmental Psychology, 14, 1-16.

Kuldas, S., Hashim, S., Ismail, H. N., \& Bakar, A. Z. (2015). Reviewing the role of cognitive load, expertise level, motivation, and unconscious processing in working memory performance. International Journal of Educational Psychology, 4, 142-169. doi:10.17583/ijep.2015.832

Kuldas, S., Ismail, H. N., Hashim, S., \& Bakar, Z. A. (2013). Unconscious learning processes: Mental integration of verbal and pictorial instructional materials. SpringerPlus, 2, 105. doi:10.1186/2193-1801-2-105

Kuldas, S., Satyen, L., Ismail, H. N., \& Hashim, S. (2014b). Greater cognitive effort for better learning: Tailoring an instructional design for learners with different levels of knowledge and motivation. Psychologica Belgica, 54, 350-373. doi:doi.org/10.5334/pb.aw

Kuyper, H., Van Der Werf, M. P. C., \& Lubbers, M. J. (2000). Motivation, metacognition, and self-regulation as predictors of long-term educational attainment. Educational Research and Evaluation, 6, 181-206. doi:10.1076/1380-3611(200009)6:3;1-A;FT181

Libet, B. (1999). Do we have free will? Journal of Consciousness Studies, 6, 4757.

Linnenbrink, E. A. (2006). Emotion research in education: Theoretical and methodological perspectives on the integration of affect, motivation, and cognition. Educational Psychology Review, 18, 307-314. doi:10.1007/s10648-006-9028-x

Linnenbrink, E. A., Ryan, A. M., \& Pintrich, P. R. (1999). The role of goals and affect in working memory functioning. Learning and Individual Differences, 11, 213-230. doi:10.1016/S1041-6080(00)80006-0

McGinnies, E. (1949). Emotionality and perceptual defence. Psychological Review, 56, 244-251. doi:10.1037/h0056508

Murphy, S. T., \& Zajonc, R. B. (1993). Affect, cognition, and awareness: affective priming with optimal and suboptimal stimulus exposures. Journal of Personality and Social Psychology, 64, 723-739. doi:10.1037/00223514.64.5.723
Oatley, K., \& Johnson-Laird, P. N. (1987). Towards a cognitive theory of emotions. Cognition and Emotion, 1(1), 29-50. doi:10.1080/02699938708408362

Öhman, A. (2002). Automaticity and the amygdala: Nonconscious responses to emotional faces. Current Directions in Psychological Science, 11, 62-66. doi:10.1111/1467-8721.00169

Öhman, A., Flykt, A., \& Esteves, F. (2001). Emotion drives attention: detecting the snake in the grass. Journal of Experimental Psychology: General, 130, 466-478. doi:10.1037/0096-3445.130.3.466

Pekrun, R. (2006). The control-value theory of achievement emotions: Assumptions, corollaries, and implications for educational research and practice. Educational Psychology Review, 18, 315-341. doi:10.1007/s10648 006-9029-9

Pekrun, R., Elliot, A. J., \& Maier, M. A. (2006). Achievement goals and discrete achievement emotions: A theoretical model and prospective test. Journal of Educational Psychology, 98, 583-597. doi:10.1037/00220663.98.3.583

Pekrun, R., Elliot, A. J., \& Maier, M. A. (2009). Achievement goals and achievement emotions: Testing a model of their joint relations with academic performance. Journal of Educational Psychology, 101, 115-135. doi: $10.1037 / \mathrm{a} 0013383$

Pekrun, R., Goetz, T., Titz, W., \& Perry, R. P. (2002). Academic emotions in students' self-regulated learning and achievement: A program of qualitative and quantitative research. Educational Psychologist, 37, 91-105. doi:10.1207/S15326985EP3702_4

Radder, H., \& Meynen, G. (2013). Does the brain "initiate" freely willed processes? A philosophy of science critique of Libet-type experiments and their interpretation. Theory \& Psychology, 23, 3-21. doi:10.1177/0959354312460926

Ritter, S. M., Van Baaren, R. B., \& Dijksterhuis, A. (2012). Creativity: The role of unconscious processes in idea generation and idea selection. Thinking Skills and Creativity, 7, 21-27. doi:10.1016/j.tsc.2011.12.002

Robinson, M. D., \& Clore, G. L. (2001). Simulation, scenarios, and emotional appraisal: Testing the convergence of real and imagined reactions to emotional stimuli. Personality and Social Psychology Bulletin, 27, 15201532. doi:10.1177/01461672012711012

Roets, A., \& Van Hiel, A. (2011). An integrative process approach on judgment and decision making: The impact of arousal, affect, motivation, and cognitive ability. The Psychological Record, 61, 497-520.

Roets, A., Van Hiel, A., \& Kruglanski, A. W. (2013). When motivation backfires: Optimal levels of motivation as a function of cognitive capacity in information relevance perception and social judgment. Motivation and Emotion, 37, 261-273. doi:10.1007/s11031-012-9299-0

Rothermund, K., Gast, A., \& Wentura, D. (2011). Incongruency effects in affective processing: Automatic motivational counter-regulation or mismatch-induced salience? Cognition and Emotion, 25, 413-425. doi:10.1080/02699931.2010.537075

Scherer, K. R. (1999). On the sequential nature of appraisal processes: Indirect evidence from a recognition task. Cognition \& Emotion, 13, 763-793. doi:10.1080/026999399379078

Scherer, K. R. (2009). The dynamic architecture of emotion: Evidence for the component process model. Cognition \& Emotion, 23, 1307-1351. doi:10.1080/02699930902928969

Schlosser, M. E. (2012). Free will and the unconscious precursors of choice. Philosophical Psychology, 25, 365-384. doi:10.1080/09515089.2011.622366

Schlosser, M. E. (2014). The neuroscientific study of free will: A diagnosis of the controversy. Synthese, 191, 245-262. doi:10.1007/s11229-0130312-2

Schooler, J. W. (2002). Representing consciousness: Dissociations between consciousness and meta-consciousness. Trends in Cognitive Science, 6, 33934. doi:10.1016/S1364-6613(02)01949-6

Schooler, J. W., Reichle, E. D., \& Halpern, D. V. (2004). Zoning out while reading: Evidence for dissociations between experience and metaconsciousness. In D. T. Levin (Ed.), Thinking and seeing: Visual metacognition in adults and children (pp. 203-226). Cambridge, MA, US: MIT Press.

Schooler, J. W., Smallwood, J., Christoff, K., Handy, T. C., Reichle, E. D., \& Sayette, M. A. (2011). Metaawareness, perceptual decoupling and the wandering mind. Trends in Cognitive Sciences, 15, 319-326. doi: 10.1016/j.tics.2011.05.006. 
Seibert, P. S., \& Ellis, H. C. (1991). Irrelevant thoughts, emotional mood states, and cognitive task performance. Memory \& Cognition, 19, 507-513. doi:10.3758/BF03199574

Senko, C., Hulleman, C. S., \& Harackiewicz, J. M. (2011). Achievement goal theory at the crossroads: Old controversies, current challenges, and new directions. Educational Psychologist, 46, 1, 26-47. doi:10.1080/00461520.2011.538646

Siegel, P., \& Weinberger, J. (2009). Very brief exposure: The effects of unreportable stimuli on fearful behavior. Consciousness and Cognition, 18, 939-951. doi:10.1016/j.concog.2009.08.001

Sio, U. N., \& Ormerod, T. C. (2009). Does incubation enhance problem solving? A meta-analytic review. Psychological Bulletin, 135, 94-120. doi: $10.1037 / \mathrm{a} 0014212$

Smallwood, J. (2013). Distinguishing how from why the mind wanders: A process-occurrence framework for self-generated mental activity. Psychological Bulletin, 139, 519-535. doi:10.1037/a0030010

Smallwood, J., \& Schooler, J. W. (2006). The restless mind. Psychological Bulletin, 132, 946-958. doi:10.1037/0033-2909.132.6.946

Smallwood, J., \& Schooler, J. W. (2013). The restless mind. Psychology of Consciousness: Theory, Research, and Practice, 1(S), 130-149. doi:10.1037/23265523.1.S. 130

Smallwood, J., Baraciaia, S. F., Lowe, M., \& Obonsawin, M. C. (2003). Task unrelated thought whilst encoding information. Consciousness and Cognition, 12, 452-484. doi:10.1016/S1053-8100(03)00018-7

Smallwood, J., Davies, J. B., Heim, D., Finnigan, F., Sudberry, M., O'Connor, R., \& Obonsawin, M. (2004). Subjective experience and the attentional lapse: Task engagement and disengagement during sustained attention. Consciousness and Cognition, 13, 657-690. doi:10.1016/j.concog.2004.06.003

Smallwood, J., Obonsawin, M. C., \& Heim, S. D. (2003). Task Unrelated Thought: The role of distributed processing. Consciousness and Cognition, 12, 169-189. doi:10.1016/S1053-8100(02)00003-X

Smith, E. R., \& DeCoster, J. (2000). Dual-process models in social and cognitive psychology: Conceptual integration and links to underlying memory systems. Personality and Social Psychology Review, 4, 108-131. doi:10.1207/S15327957PSPR0402_01
Solms, M., \& Panksepp, J. (2012). The "Id" knows more than the "Ego" admits: Neuropsychoanalytic and primal consciousness perspectives on the interface between affective and cognitive neuroscience. Brain Sciences, 2, 147-175. doi:10.3390/brainsci2020147

Soon, C. S., Brass, M., Heinze, H. J., \& Haynes, J. D. (2008). Unconscious determinants of free decisions in the human brain. Nature neuroscience, 11, 543545. doi: $10.1038 / \mathrm{nn} .2112$

Sweller, J., Ayres, P., \& Kalyuga, S. (2011). Cognitive load theory. New York: Springer.

Wegner, D. M. (1997). Why the mind wanders. In J. D. Cohen \& J. W. Schooler (Eds.), Scientific approaches to consciousness (pp. 295-315). Mahway, NJ: Erlbaum.

Wegner, D. M. (2002). The illusion of conscious will. Cambridge, MA: MIT Press.

Wegner, D. M., \& Wheatley, T. (1999). Apparent mental causation: Sources of the experience of will. American Psychologist, 54, 480-492. doi:10.1037/0003-066X.54.7.480

Westen, D. (1998). The scientific legacy of Sigmund Freud: Toward a psychodynamically informed psychological science. Psychological Bulletin, 124, 333-371. doi:10.1037/0033-2909.124.3.333

Westen, D. (1999). The scientific status of unconscious processes: is Freud really dead? Journal of the American Psychoanalytic Association, 47, 10611106. doi: $10.1177 / 000306519904700404$

Westen, D. (2006). Implications of research in cognitive neuroscience for psychodynamic psychotherapy. Focus, 4, 215-222.

Winkielman, P., \& Berridge, K. C. (2004). Unconscious emotion. Current Directions in Psychological Science, 13, 120-123. doi:10.1111/j.09637214.2004.00288.x

Wrosch C., Scheier, M. F., Miller, G. E., Schulz, R., \& Carver, C. S. (2003) Adaptive self-regulation of unattainable goals: Goal disengagement, goal reengagement, and subjective well-being. Personality and Social Psychology Bulletin, 29, 1494-1508. doi:10.1177/0146167203256921

(Article received: 01-07-2015; revised: 13-11-2015; accepted: 15-11-2015) 